\title{
Retardation of rabbit nictitating membrane conditioning following US preexposures depends on the distribution and number of US presentations
}

\author{
MICHAEL E. SALADIN, WILLIAM N. TEN HAVE, ZALMAN L. SAPER, \\ JORDAN S. LABINSKY, and ROBERT W. TAIT \\ University of Manitoba, Winnipeg, Manitoba, Canada
}

\begin{abstract}
Retarded conditioned response (CR) acquisition produced by unconditioned stimulus (US) preexposures has been attributed either to interference resulting from contextual conditioning or to habituation of the US. Both perspectives assume that the amount of retardation is directly related to the number of US preexposures. This assumption was examined in two experiments. In Experiment 1, separate groups of rabbits received 200 paraorbital shock US preexposures either in one session or spread equally over 10 daily sessions. Subsequently, all subjects received 150 CS-US pairings. Acquisition of nictitating membrane CRs was retarded relative to a naive control group only in the group that received the preexposures over 10 sessions. Thus, the number of US preexposure sessions, rather than the number of US preexposures, determined whether or not retarded acquisition was observed. In Experiment 2, four groups of rabbits received 1, 5, 20 , or 40 shock US preexposures in each of 10 sessions. Over the subsequent 150 CS-US pairings, similar levels of retarded CR acquisition were observed in groups that received 20 and 40 US preexposures per session, a weak retardation effect was observed with 5 preexposures per session, and no retardation was observed with 1 preexposure per session. Thus, Experiment 2 suggested that retarded CR development was not greatly influenced by increasing the number of US preexposures above some minimum threshold number of exposures per session. Implications for current theories were discussed.
\end{abstract}

Associative and nonassociative theoretical models have been developed to account for the observation that prior experience with an unconditioned stimulus (US) results in retarded conditioned response (CR) acquisition during pairings of the US with a conditioned stimulus (CS) (see Saladin \& Tait, 1986). Two associative models, the context blocking (Mis \& Moore, 1973; Randich \& LoLordo, 1979; Tomie, 1976; Tomie, Murphy, Fath, \& Jackson, 1980 ) and comparator (Gibbon \& Balsam, 1981; Jenkins, Barnes, \& Barrera, 1981) models, propose that US preexposures result in the development of an excitatory context-US association. The context blocking model posits that CR development is retarded during subsequent CS-US conditioning because the already established associative strength of the context "blocks" (Kamin, 1968, 1969 ) or competes with the discrete CS for the associative strength supported by the US (Rescorla \& Wagner, 1972). The comparator model argues that the retardation

This research was supported by Grant A0312 from the Natural Sciences and Engineering Research Council of Canada to R. W. Tait. Michael Saladin was supported by a postgraduate scholarship from the Natural Sciences and Engineering Research Council of Canada. Requests for reprints should be addressed to R. W. Tait, Psychology Department, P515 Duff Roblin Building, University of Manitoba, Winnipeg, Manitoba R3T 2N2, Canada. effect is a performance, rather than an associative, deficit. For Gibbon and Balsam (1981), performance occurs when the CS expectancy for the US's occurrence (designated $\left.h_{t}\right)$ is high relative to the context expectancy for the US (designated $h_{\mathrm{c}}$ ). Since the context develops a high expectancy for the US occurrence during US preexposures (i.e., $h_{\mathrm{c}}>0=h_{\mathrm{t}}$ ), subsequent CR performance will be retarded because a greater number of CS-US pairings will be necessary to generate the high CS expectancy (i.e., $h_{\mathrm{t}}>h_{\mathrm{c}}$ ) needed for the observation of CR performance. In contrast to the associative theories, nonassociative habituation models argue that US preexposures result in a reduction in the subject's responsiveness to the US (e.g., Solomon \& Corbit, 1974; Taylor, 1956). As a consequence, $\mathrm{CR}$ development during subsequent conditioning with the less effective US will be attenuated.

All theoretical accounts agree that the magnitude of the retardation effect should be directly related to the number of prior US preexposures. The context blocking model (see Tomie, 1976) asserts that increasing the number of US preexposures increases the proportion of the US's finite associative strength acquired by the context, and thereby diminishes the amount of associative strength that is subsequently obtainable by the CS (i.e., the presentation of each US alone results in an increment in associative strength to the context). Gibbon and Balsam's (1981) 
comparator model asserts that the context expectancy for the US is a positive function of the number of US preexposures per unit time (i.e., density). Because the observation of CRs during subsequent conditioning requires that the CS expectancy for the US $\left(h_{t}\right)$ be greater than the context expectancy for the US $\left(h_{c}\right)$, the scalar expectancy model predicts that the number of CS-US pairings required to produce $C R s$ would be positively related to the number of prior US preexposures. Finally, nonassociative habituation models (e.g., Taylor, 1956) argue that increasing the number of US preexposures results in increasing levels of habituation to the US, thereby rendering the US increasingly less effective for subsequent CS-US conditioning. Thus, all models of the US preexposure effect anticipate a positive relationship between the number of US preexposures and the magnitude of retarded $C R$ acquisition observed during subsequent CS-US conditioning.

Three studies have tested the predicted direct relation between the number of US preexposures and the magnitude of retarded CR acquisition observed during subsequent CS-US conditioning (Hobson, 1968; Mis \& Moore, 1973; Randich \& LoLordo, 1979). In general, the studies reported confirmation of the predicted direct relationship (but see Hobson, 1968); however, two of the studies (Mis \& Moore, 1973; Randich \& LoLordo, 1979) confounded the number of US preexposures with the number of sessions of the US preexposure treatment. More precisely, subjects that received a greater number of US preexposures also received more sessions of preexposures.

The purpose of the present experiments was to examine the relationship between the number of US preexposures and the magnitude of the retardation effect when the number of preacquisition US presentations and the number of sessions of US preexposures were manipulated separately. In Experiment 1, the number of preacquisition US presentations was held constant while the effects of the number of sessions of US preexposures on subsequent CS-US conditioning were examined. In Experiment 2 , the number of sessions of US preexposures was held constant while the effects of the number of preacquisition US presentations on subsequent CS-US conditioning were examined.

\section{EXPERIMENT 1}

Saladin and Tait (1986) showed that retarded nictitating membrane conditioning can be observed following 10 daily sessions of 20 paraorbital shock US preexposures. Since it is known that retarded acquisition results from 200 US preexposures distributed over 10 sessions, it would follow from all the theoretical models of US preexposure effects that receiving 200 US preexposures distributed over one daily session should result in a retarded rate of acquisition that is comparable to receiving the same number of US presentations over 10 daily sessions. This expectation was evaluated in Experiment 1 in which two groups of rabbit subjects received 200 US preexposures distributed over 1 or 10 daily sessions. A third group did not receive any US preexposures and was included to detect the effects of US preexposures in the other two groups. Following the US preexposure phase, the three groups received $150 \mathrm{CS}-\mathrm{US}$ conditioning trials.

\section{Method}

Subjects. Twenty-four naive male and female New Zealand white rabbits weighing between 1.5 and $2.5 \mathrm{~kg}$ were obtained from the Blue Farm Rabbitry in Lockport, Manitoba. All subjects were housed separately in $60 \times 45 \mathrm{~cm}$ wire-mesh cages and were given free access to food and water.

Apparatus. Conditioning of the rabbit's nictitating membrane response was conducted in an apparatus described in detail by Gormezano (1966). Briefly, the subjects were placed in a Plexiglas restraining box; the head was fixed in position by foam pinnae clamps; the right eyelids were held open by Newery tailor hooks that were attached to a bipartite Velcro strip that was adjusted to fit securely around the rabbit's head; and a headmount was tightly positioned over the rabbit's snout. The piano wire armature of a $10 \mathrm{~K}$ microtorque potentiometer that was fixed to the headmount was coupled to a previously implanted $2.0-\mathrm{mm}$ loop of 2.0 Ethicon suture by a staple and thread. The restraining box and the transducing apparatus were enclosed together in one of eight identical, ventilated, fireproof, legal-size, file cabinet chambers. The US was a $4.0-\mathrm{mA}, 100-\mathrm{msec}, 60-\mathrm{Hz}$, constant-current shock delivered totwo stainless steel $9-\mathrm{mm}$ Autoclips implanted $10 \mathrm{~mm}$ behind and $10 \mathrm{~mm}$ above and below the horizontal plane of the right eye. The CS was a 600-msec, 20-psi airpuff delivered to the animal's left abdominal region. Continuous masking white noise was presented in the experimental room at $72 \mathrm{~dB}$. A software system modified from Tait and Gormezano (1974), implemented on an 8K Raytheon 703 computer, controlled the delivery of stimuli and the recording of responses. Nictitating membrane extensions greater than or equal to $0.5 \mathrm{~mm}$ were defined as responses.

Procedure. Two days after their arrival, all subjects had sutures implanted in their right nictitating membrane, and the Autoclip sutures were implanted. Two days after surgery, the subjects were randomly assigned to three groups (Groups $10 \times 20,1 \times 200$, and NPSIT). On the 10 days that followed, Group $10 \times 20(N=8)$ received $20 \mathrm{US}$ preexposures in each of 10 daily sessions, whereas Group $1 \times 200(N=8)$ remained in their home cages for 9 days before receiving 200 US preexposures in 1 session. Subjects in the naive control group, Group NPSIT $(N=8)$, were left undisturbed in their home cages to preclude the development of latent inhibition effects to the context that might result from exposure to the context during the preexposure phase. Following the preexposure phase, all three groups received $150 \mathrm{CS}-\mathrm{US}$ conditioning trials in 1 session. Throughout the experiment, the mean intertrial interval was $1 \mathrm{~min}$. In addition, on all paired trials, CS onset preceded US onset by $500 \mathrm{msec}$.

The criterion for a CR or UR was set at $.5 \mathrm{~mm}$ of movement of the nictitating membrane during the CS or US, respectively. In both cases, $.5 \mathrm{~mm}$ of movement of the nictitating membrane corresponded to a change of $.1 \mathrm{~V}$ in the potentiometer, which in turn corresponded to a hexadecimal output of 10 in the analog-to-digital conversion system. During the US preexposure phase, the maximum or peak amplitude (i.e., the largest change from the pre-US baseline voltage input to the analog-to-digital converter that occurred in a 500-msec interval following US onset) of the UR was recorded for all subjects in groups that received US preexposure. 


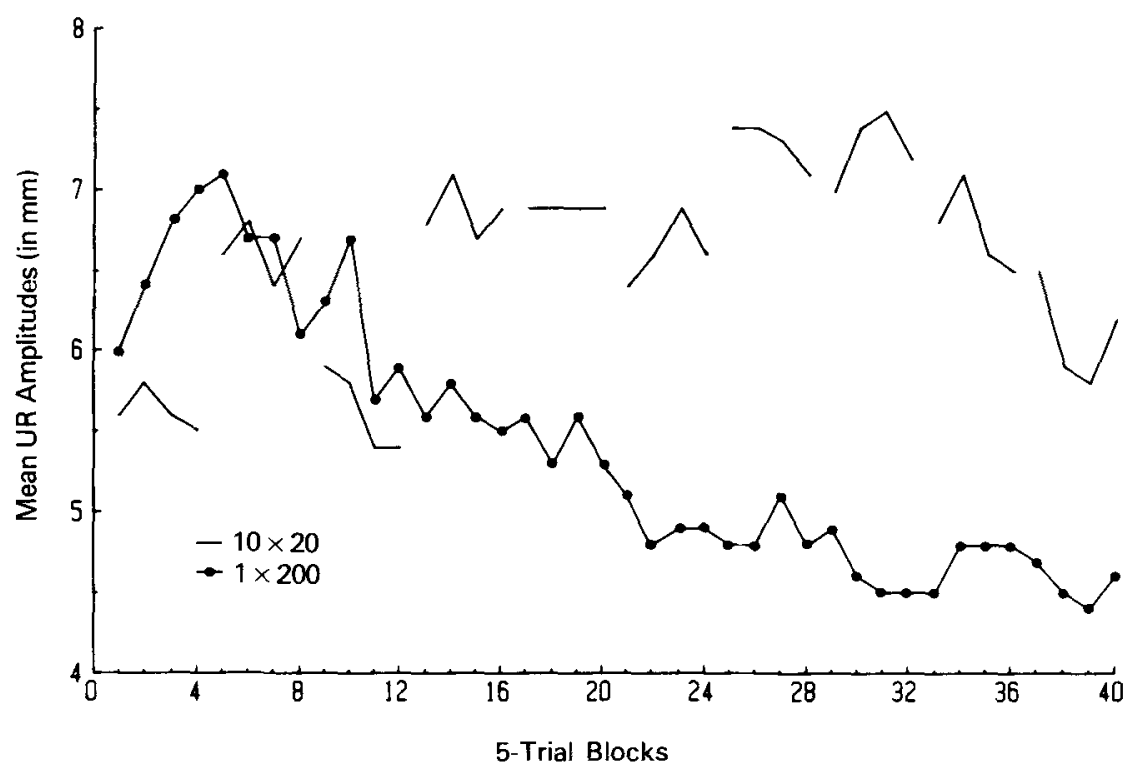

Figure 1. The mean unconditioned response (UR) peak amplitude for each of the 40 fivetrial blocks of unconditioned stimulus preexposures in Experiment 1 for Groups $10 \times 20$ and $1 \times 200$.

\section{Results}

Preexposure phase. Figure 1 depicts the mean UR peak amplitudes for each of the $\mathbf{4 0}$ five-trial blocks of US preexposures for Groups $10 \times 20$ and $1 \times 200$. The function for Group $10 \times 20$ is broken at the transition between each of the 10 days of preexposure in order to illustrate the change in peak UR amplitude that occurred over the days. The figure shows that the mean UR peak amplitudes of Group $1 \times 200$ systematically decreased to low levels during the US preexposure phase, whereas those of Group $10 \times 20$ nonmonotonically increased during the initial 32 blocks before evidencing a decrease during the last 8 blocks. A repeated measures analysis of variance (ANOVA) with the $\mathbf{4 0}$ five-trial blocks as a repeated factor confirmed the divergent trends of Groups $10 \times 20$ and $1 \times 200$ by yielding a significant block $\times$ group $[F(39,546)$ $=4.98, p<.01]$ interaction with significant linear $[F(1,14)=12.14, p<.01]$ and quadratic $[F(1,14)=$ $6.18, p<.05]$ orthogonal components for trend. Orthogonal components for trend applied to each group yielded only a significant decreasing linear component for Group $1 \times 200[F(1,7)=17.28, p<.01]$ and only a significant quadratic component for Group $10 \times 20[F(1,7)$ $=6.33, p<.05]$. The significant linear trend component statistically confirms the decreasing UR peak amplitudes of Group $1 \times 200$, whereas the quadratic trend component statistically confirms the rise and subsequent fall in the UR peak amplitudes of Group $10 \times 20$.

A separate analysis was conducted on Group $10 \times 20$ with days and the four five-trial blocks within each day as repeated factors. No within-session effects were identified by the ANOVA for Group $10 \times 20[F(3,21)=1]$.
The analysis revealed only a significant days main effect $[F(9,63)=2.14, p<.05]$, which contained only a significant quadratic trend component $[F(1,7)=6.06$, $p<.05]$. The significant quadratic trend component confirms the above-noted increase and subsequent decrease in UR peak amplitudes of Group $10 \times 20$ across daily sessions of US preexposure.

Conditioning phase. The mean percentages of CRs for Groups $10 \times 20,1 \times 200$, and NPSIT over the 1510 -trial blocks of acquisition training were 42,63 , and 67 , respectively. An a posteriori orthogonal contrast applied to the group means revealed that CR performance was lower in Group $10 \times 20$ than in Groups $1 \times 200$ and NPSIT $[F(1,21)=4.38, p<.05]$, which did not differ from each other $[F(1,21)<1]$. Thus, retarded acquisition was observed only in Group $10 \times 20$, which received 200 US preexposures distributed over 10 sessions.

Figure 2 depicts the mean percentage of CRs during the 15 10-trial blocks of conditioning for Groups $10 \times 20$, $1 \times 200$, and NPSIT. The figure shows that CRs gradually increased over blocks of conditioning trials for all three groups. A significant blocks main effect $[F(14,294)$ $=33.60, p<.01]$ yielded by a repeated measures ANOVA statistically confirmed that all groups acquired CRs during conditioning. The figure also shows that the initial occurrence of CRs was retarded in Group $10 \times 20$, but once $\mathrm{CR}$ acquisition commenced, it occurred at about the same rate as in Groups $1 \times 200$ and NPSIT. The $a b-$ sence of a block $\times$ group interaction $[F(28,294)<1]$ in the repeated measures ANOVA is consistent with the apparent parallel acquisition functions. Therefore, 200 US preexposures, given in either 1 or 10 sessions does not 


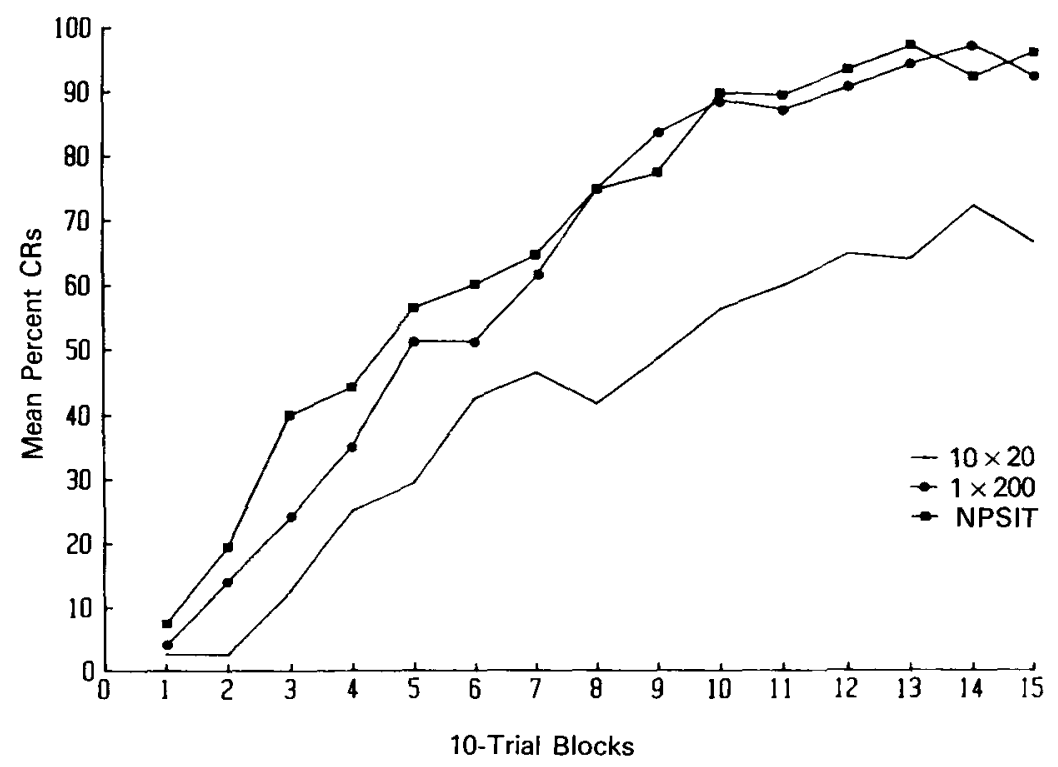

Figure 2. The mean percentage of conditioned responses (CRs) during the 1510 trial blocks of conditioning for Groups $10 \times 20,1 \times 200$, and NPSIT in Experiment 1 .

appear to influence the rate of NM CR acquisition, once conditioning commences.

\section{Discussion}

Experiment 1 reproduced three effects that have been reported previously. First, during the preexposure phase Group $10 \times 20$ showed an initial increase in daily UR amplitudes that is consistent with previous reports of increases in UR amplitude over successive preexposure sessions (Mis \& Moore, 1973; Saladin \& Tait, 1986; Suboski, DiLollo, \& Gormezano, 1964). However, it should be noted that the decline in the UR amplitudes observed over the last 2 days of preexposure in Group $10 \times 20$ is atypical and reflects the contribution of a large decrease in UR amplitude of a single subject. Neither our previous research (Saladin \& Tait, 1986) nor our subsequent research (Saladin \& Tait, 1988) has produced a subject that showed a similar pattern of UR changes. Second, the retardation of the onset of conditioning in Group $10 \times 20$ replicated previous studies that showed that 20 paraorbital shock US preexposures in each of 10 successive sessions produced retardation of excitatory nictitating membrane (Saladin \& Tait, 1986) and eyelid (Hinson, 1982) conditioning in the rabbit. Finally, the retardation of conditioning was demonstrated only in the group that showed an increase in mean UR amplitudes during US preexposure. Similar concordance between retarded acquisition and increases in UR amplitudes have been reported by Mis and Moore (1973) and Saladin and Tait (1986).

The most notable observation from Experiment 1 was the absence of a preexposure effect on the acquisition of Group $1 \times 200$. Group $1 \times 200$ received the same number of USs, the same density of USs, and the same total du- ration of exposure to the conditioning context as did Group $10 \times 20$. Therefore, the groups should have had equivalent terminal levels of contextual conditioning. Given equivalence in the amount of contextual conditioning, both the contextual conditioning (Tomie, 1976) and the comparator (Gibbon \& Balsam, 1981; Jenkins et al., 1981) models expect similar US preexposure effects on conditioning. Because Group $10 \times 20$, but not Group $1 \times 200$, showed retarded acquisition during conditioning, the results of Experiment 1 are inconsistent with the theoretical expectations.

\section{EXPERIMENT 2}

Experiment 1 demonstrated that the number of sessions of US preexposures is an important determining factor for the US-preexposure-produced retardation effect. Previous studies have reported either a positive relationship between the number of US preexposures and the magnitude of the retardation effect (Mis \& Moore, 1973) or a positive relationship between the number of US preexposure sessions and the magnitude of the retardation effect (Randich \& LoLordo, 1979). However, these studies either failed to equate the number of sessions of US preexposures while examining the relationship between the number of US preexposures and subsequent levels of retardation (Mis \& Moore, 1973) or failed to equate the number of US preexposures while examining the relationship between the number of sessions of US preexposure and subsequent levels of retardation (Randich \& LoLordo, 1979). Thus, a question that remains is whether or not the positive relationship between the number of US preexposures and the magnitude of the retardation effect will be maintained when the number of 
sessions of US preexposures is held constant. According to the context blocking (Tomie, 1976), comparator (Gibbon \& Balsam, 1981), and habituation (e.g., Solomon \& Corbit, 1974; Taylor, 1956) models, a positive relationship should be observed.

Experiment 2 examined the relationship between the number of US preexposures and the magnitude of the retardation effect while holding constant the number of sessions of US preexposures. To accomplish this objective, four groups of rabbits received $1,5,20$, or 40 paraorbital shock US preexposures during each of 10 daily sessions. Where multiple shocks occurred within a session, shock density was equated. A fifth group, which did not receive US preexposures, was included to provide a contrast in order to detect the effects of the US preexposures. Following the US preexposure phase, all subjects received $150 \mathrm{CS}-\mathrm{US}$ conditioning trials.

\section{Method}

Subjects. Eighty naive male and female New Zealand white rabbits, weighing between 1.5 and $2.5 \mathrm{~kg}$, served as subjects.

Apparatus. The apparatus was identical to that described for Experiment 1.

Procedure. Surgical preparation, recovery, and group assignment procedures were the same as those employed in Experiment 1. Moreover, the experimental parameters and criterion for CRs and URs were identical to those employed in Experiment 1.

Four groups of rabbit subjects, designated Groups $10 \times 1,10 \times 5$, $10 \times 20$, and $10 \times 40$, received $1,5,20$, and 40 US preexposure(s), respectively, in each of 10 daily sessions. A fifth group of subjects (designated Group NPSIT) was left undisturbed in their home cages throughout the preexposure phase. Following the US preexposure phase, $150 \mathrm{CS}$-US pairings were given to all five groups, as in Experiment 1 .

Originally, 16 subjects were assigned to each of the five designated groups. However, 1 subject in Group $10 \times 5$ had to be dis- carded due to illness. Thus, Groups $10 \times 40,10 \times 20,10 \times 5,10 \times 1$, and NPSIT contained $16,16,15,16$, and 16 subjects, respectively.

\section{Results}

Preexposure phase. To determine UR amplitude differences between the groups during the preexposure phase, we applied a repeated measures ANOVA to the daily mean UR peak amplitudes for each subject. Within-session changes in UR amplitudes were determined for Groups $10 \times 40$ and $10 \times 20$ by applying separate ANOVAs to the mean UR peak amplitudes calculated for each block of five trials.

The mean UR peak amplitudes for Groups $10 \times 40$, $10 \times 20,10 \times 5$, and $10 \times 1$ over the 10 days were $7.1,7.1$, 6.9 , and 5.9, respectively. A posteriori orthogonal contrasts revealed that the UR peak amplitude of Group $10 \times 1$ was lower than the amplitudes of Groups $10 \times 40,10 \times 20$, and $10 \times 5[F(1,59)=6.06, p<.01]$, which did not differ from one another [all $\left.F_{\mathrm{S}}(1,59)<1\right]$.

Figure 3 depicts the mean UR peak amplitudes for each of the 10 days of US preexposures for Groups $10 \times 40$, $10 \times 20,10 \times 5$, and $10 \times 1$. The figure shows that the mean UR peak amplitudes of Groups $10 \times 40,10 \times 20$, and $10 \times 5$ systematically increased over days of US preexposure, whereas those of Group $10 \times 1$ did not. Orthogonal components for trend applied to the days effect of each group revealed significant linear components for Groups $10 \times 40$ $[F(1,15)=13.31, p<.01], 10 \times 20[F(1,15)=7.67$, $p<.01]$, and $10 \times 5[F(1,14)=12.37, p<.01]$, but not for Group $10 \times 1[F(1,15)=1.86]$. Thus, the analyses confirmed that the UR amplitudes of Groups $10 \times 40$, $10 \times 20$, and $10 \times 5$ increased over days of US preexposure, whereas those of Group $10 \times 1 \mathrm{did}$ not.

Finally, the examination of Groups $10 \times 40$ and $10 \times 20$

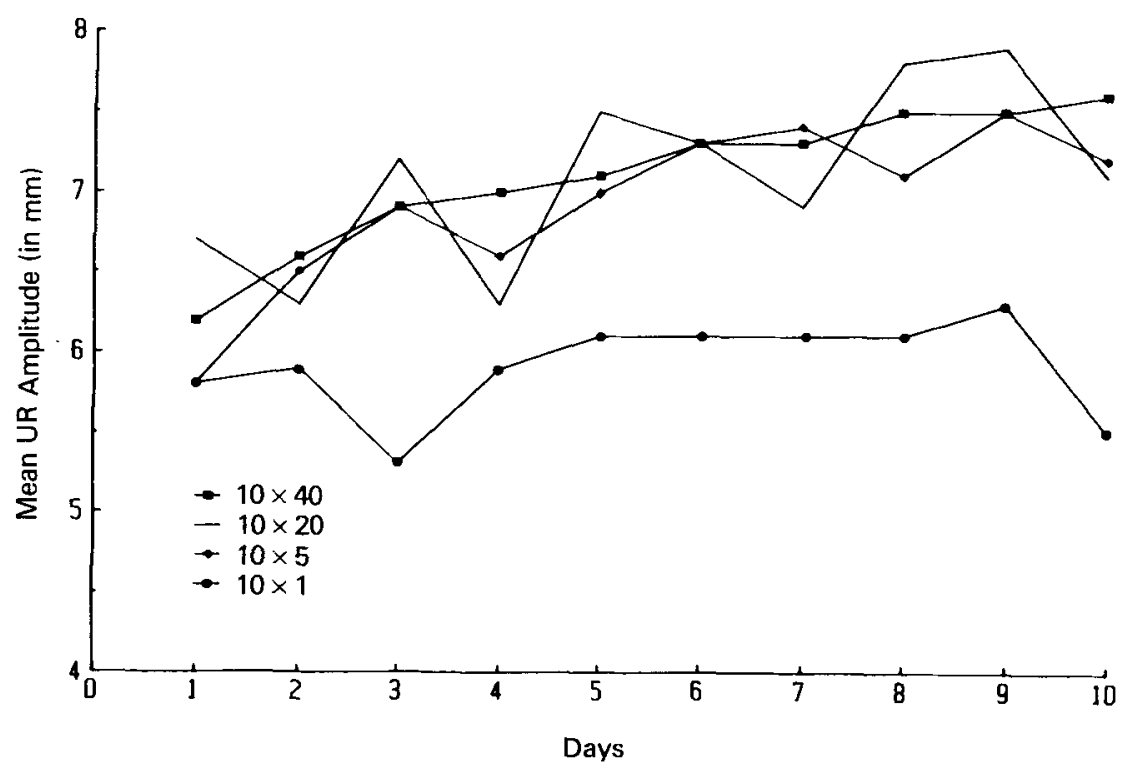

Figure 3. The mean unconditioned response (UR) peak amplitudes for each of the 10 daily sessions of unconditioned stimulus preexposures in Experiment 2 for Groups $10 \times 40$, $10 \times 20,10 \times 5$, and $10 \times 1$. 
for within-session changes in mean UR peak amplitude suggested that Group $10 \times 40$ evidenced a within-session UR amplitude decrement, but that Group $10 \times 20$ did not. Collapsed across days, the mean UR peak amplitude of Group $10 \times 40$ decreased from a value of $7.5 \mathrm{~mm}$ on the first five-trial block to a value of $6.9 \mathrm{~mm}$ on the eighth five-trial block. A repeated measures ANOVA yielded a significant blocks main effect for Group $10 \times 40$ $[F(7,105)=7.45, p<.01]$, which contained only a significant linear trend component $[F(1,15)=14.91$, $p<.011$. On the other hand, the ANOVA for Group $10 \times 20$ did not contain a significant block effect $[F(3,45)$ $=1.25]$. Thus, the analyses verified that Group $10 \times 40$ showed a systematic within-session decrement in UR amplitude but, as in Experiment 1, Group $10 \times 20$ did not.

Conditioning phase. The mean percentages of CRs of Groups $10 \times 40,10 \times 20,10 \times 5,10 \times 1$, and NPSIT over the 15 10-trial blocks of acquisition training were 55, 54, 68,74 , and 68 , respectively. A posteriori orthogonal contrasts applied to the group means revealed that CR performance was lower in Groups $10 \times 40$ and $10 \times 20$ than in Groups $10 \times 5,10 \times 1$, and NPSIT $[F(1,74)=10.32$, $p<.01$ ]; the difference between Groups $10 \times 40$ and $10 \times 20$ was not significant $[F(1,74)<1]$; and no differences among Groups $10 \times 5,10 \times 1$, and NPSIT reached significance $\left[F_{\mathrm{s}}(1,74)<1\right]$. Additionally, a series of a posteriori contrasts were performed on the group means obtained during the initial two blocks of acquisition to determine if any early transient retardation effects may have occurred at the onset of conditioning. The analysis revealed that the CR performance of Group $10 \times 5(M=5.5)$ was lower than that observed for Groups NPSIT $(M=15.7)$ and $10 \times 1(M=17.3)[F(1,74)=9.69$, $p<.01]$. Thus, protracted retardation effects were observed only in Groups $10 \times 20$ and $10 \times 40$, whereas a transient retardation effect was identified in Group $10 \times 5$ at the onset of conditioning.

Figure 4 depicts the mean percentage of CRs during the 1510 -trial blocks of conditioning for Groups $10 \times 40$, $10 \times 20,10 \times 5,10 \times 1$, and NPSIT. The figure shows that, for all five groups, CRs increased over blocks of conditioning trials. A significant blocks main effect $[F(14,1036)$ $=136.65, p<.01]$, found in a repeated measures ANOVA, statistically confirmed that all groups acquired CRs during conditioning. The figure also shows that $C R$ acquisition occurred at about the same rate in all groups despite any protracted or transient retardation effects. The absence of a block $\times$ group interaction $[F(56,1036)<1]$ is consistent with the apparent parallel acquisition functions. Thus, US preexposures do not appear to influence the rate of NM CR acquisition.

\section{Discussion}

During the preexposure phase, Groups $10 \times 5,10 \times 20$, and $10 \times 40$ replicated previously reported results (Mis \& Moore, 1973; Saladin \& Tait, 1986, 1988; Suboski et al., 1964) by evidencing increases in UR amplitude over successive days of preexposure. The absence of a UR amplitude increase in Group $10 \times 1$ suggests that repeated exposures to the USs within each preexposure session creates the conditions needed for the effect. It should be noted that the UR amplitude increase over days for Group $10 \times 40$ occurred despite the reliable decrease in amplitude that occurred within each session. The within-session decrement, which was also observed in Group $1 \times 200$ in Experiment 1, is consistent with the expectations of non-

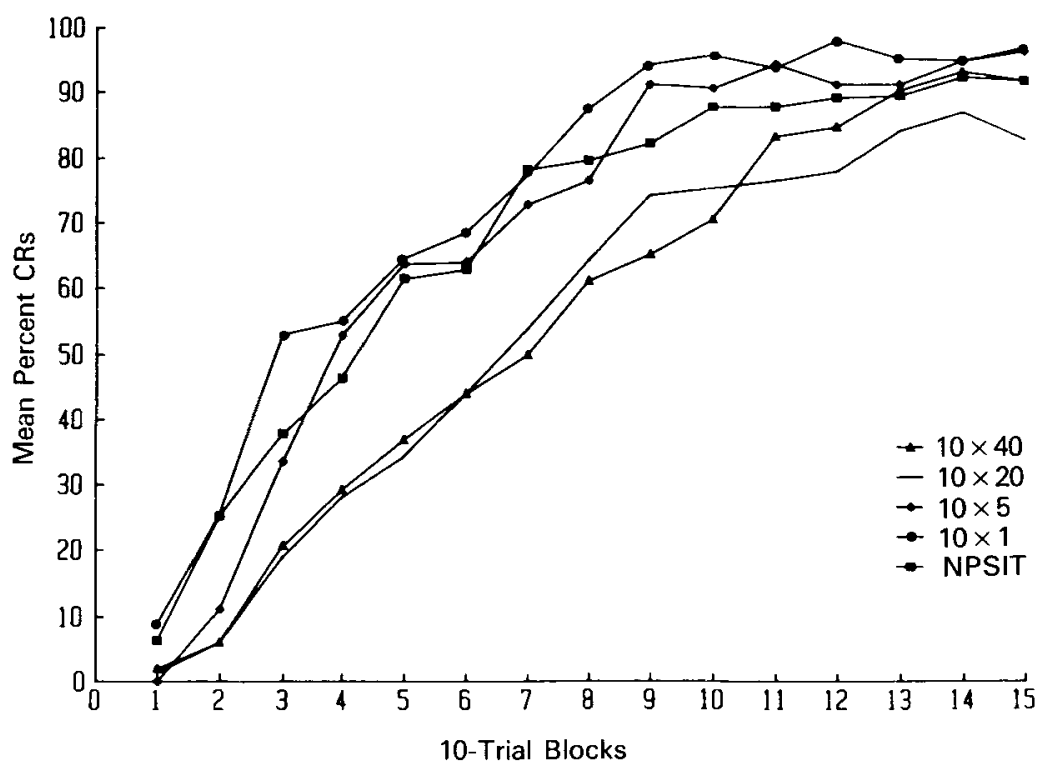

Figure 4. The mean percentage of conditioned responses (CRs) during the 1510 trial blocks of conditioning for Groups $10 \times 40,10 \times 20,10 \times 5,10 \times 1$, and NPSIT in Experiment 2. 
associative (Solomon \& Corbit, 1974; Taylor, 1956) models. The absence of a within-session decrement in Group $10 \times 20$ suggests that between 20 and 40 US occurrences are required for our conditioning parameters to produce a measurable habituation-like effect.

As in Experiment 1, there was a concordance between the increase in UR amplitudes over days and the subsequent retardation of CR acquisition. Group $10 \times 1$, which showed no increase in amplitude, failed to demonstrate retarded acquisition. Each of the other preexposed groups demonstrated both an increase in daily UR amplitude and retarded acquisition. However, UR amplitude change was not a perfect predictor of the amount of retardation of acquisition. Equivalent increases in daily UR amplitudes were obtained for Groups $10 \times 5,10 \times 20$, and $10 \times 40$, yet the amount of retardation observed in Group $10 \times 5$ was much less than that observed in Groups $10 \times 20$ and $10 \times 40$, which did not differ from one another.

The present results are inconsistent with the current theoretical accounts of US preexposure effects. The context blocking (Tomie, 1976), comparator (Gibbon \& Balsam, 1981), and habituation (e.g., Solomon \& Corbit, 1974; Taylor, 1956) models all assert that there should be a direct relationship between the number of US preexposures and the magnitude of the retardation effect. In the present study, a weak retardation effect was observed after 50 preexposures (Group $10 \times 5$ ), and similar levels of retarded acquisition were observed in the groups that received either 200 or $\mathbf{4 0 0}$ US preexposures. Thus, the results indicate that the retardation effect is produced by some minimum critical number of US preexposures (i.e., greater than 50 but less than 200 US preexposures) and that extending US preexposures beyond the minimum critical number does not greatly increase the degree of retarded acquisition.

It is possible that if additional preexposure sessions had been given, retardation effects could have developed in Group $10 \times 1$ and stronger effects found in Group $10 \times 5$. Such an observation would have two implications. First, it would challenge the hypothesis that a threshold number of US preexposures per session is critical in determining the CR retardation effect. Instead, it would imply that the learning processes that produce the US preexposure effects were incomplete in the present study. Second, such an observation would strengthen the assertion that the number of discrete sessions is a critical variable in determining retarded CR development, because the observation implies the convergence of groups that received dramatically different numbers of US preexposures per session.

\section{GENERAL DISCUSSION}

To account for the retardation of $C R$ acquisition by preexposure to USs, two questions need to be answered: What are the processes that are activated when repeated US-alone presentations are given? How do such processes interact with discrete cue conditioning mechanisms to yield proactive effects?

For nonassociative models (LoLordo \& Randich, 1981; Solomon \& Corbit, 1974; Taylor, 1956), the answer to the two questions is a unifactor approach that postulates that US preexposures produce a reduction in the effectiveness of the US, which has the consequence of slowing discrete cue conditioning because a less effective US is being employed. Three aspects of the present results are inconsistent with this unifactor approach. First, nonassociative models would expect a correlation between UR diminution during preexposure with subsequent retarded CR acquisition. Both Groups $1 \times 200$ (Experiment 1) and $10 \times 40$ (Experiment 2) showed reliable UR decrease in UR amplitude. However, only the latter group displayed retardation of $C R$ acquisition. Second, when presented with evidence that UR amplitudes increased with repeated US preexposures, proponents of nonassociative models would have to conclude that sensitization-like effects, which would yield a more effective US, had occurred. As a consequence, the models would expect that increased UR amplitudes over US preexposure should correlate with facilitated $\mathrm{CR}$ acquisition. In the present studies, which replicated previous observations (Mis \& Moore, 1973; Saladin \& Tait, 1986), all groups that showed an increase in UR amplitude over days of preexposure also demonstrated retarded $\mathrm{CR}$ acquisition. Finally, if US preexposures result in a reduction in the effectiveness of the US, then subsequent differences in CR acquisition should mimic the effects of US intensity manipulations. In rabbit NM conditioning, US intensity manipulations result in differences in rates of acquisition (Moore \& Gormezano, 1977; Smith, 1968). In the present experiments, the onset of conditioning was retarded, but not its subsequent rate. Thus, the present results suggest that although US preexposures may activate processes that are consistent with the nonassociative models, such processes are not major determinants of subsequent retarded acquisition.

In contrast to nonassociative models, the context blocking (Randich \& LoLordo, 1979; Tomie, 1976) and comparator (Gibbon \& Balsam, 1981; Jenkins et al., 1981) associative models assume that separate processes are needed to answer the two questions. Both positions assert that during the US preexposure phase, context conditioning occurs, presumably through the same mechanisms that produce conditioning to discrete CSs. During subsequent discrete cue conditioning, proactive effects result from the interference either with the development of associations by mechanisms (Randich \& LoLordo, 1979; Tomie, 1976) that are analogous to the RescorlaWagner account of blocking (Rescorla \& Wagner, 1972) or with CR performance by biasing the comparator ratio that determines performance (Gibbon \& Balsam, 1981; Jenkins et al., 1981). For both positions, the amount of interference will be directly related to the degree of context conditioning established during the US preexposure phase. 
In a general sense, the current results are consistent with associative accounts. In Experiment 1, retarded CR acquisition occurred with multiple sessions, but not with a single session of US preexposures. This observation parallels the observation that discrete cue conditioning is superior when a fixed number of trials are distributed over sessions of conditioning relative to their occurrence in a single session (Kehoe \& Gormezano, 1974; Leventhal, 1973). In Experiment 2, retarded CR acquisition was relatively insensitive to the number of US preexposures presented within each session. Again, the results paralleled discrete cue conditioning results in which limited improvement in CR performance is observed with large increments in the number of paired trials per session (Kehoe \& Gormezano, 1974). With both the US preexposure and discrete cue phenomena, the insensitivity appears after some critical value of trials per session is exceeded. Thus, both the retardation effect of US preexposures and discrete cue conditioning appear to be nonmonotonically related to the number of trials per session. Because the context blocking and comparator models expect that the degree of retardation reflects the associative properties of the context and that the associative processes involved in context conditioning and discrete cue conditioning are the same, our observations of parallels between the retardation effects of US preexposures and discrete cue conditioning are consistent with the associative models.

Despite the apparent consistency with associative models, our results are incompatible with the details of both models. The models fail to account for either the changes observed during the preexposure phase or the differences observed during $C R$ acquisition.

Although the context blocking (Randich \& LoLordo, 1979; Tomie, 1976) and comparator models (Gibbon \& Balsam, 1981; Jenkins et al., 1981) are silent on issues regarding response rules, both models argue that common mechanisms underlie both context-US and CS-US associations. Therefore, changes in response topography that occur during US preexposures should mimic those that are observed during discrete trial conditioning. During discrete cue conditioning, as the CS acquires an excitatory association, mean UR amplitudes decrease (Donegan, 1981; Kimmel, 1966; Terry, 1976; but see Desmond, Romano, \& Moore, 1980). Accordingly, associative theories of the US preexposure effect would expect a parallel behavioral outcome as the subject learns to expect the US in a context. In Experiments 1 and 2 (see also Saladin \& Tait, 1986) increases, not decreases, in daily mean UR amplitudes were the best predictor of subsequent retarded conditioning. The lack of concordance between a decrease in UR amplitudes and subsequent retarded conditioning indicates that either there is not a parallel between the behavioral effects on URs of contextual conditioning and discrete cue conditioning, or that excitatory conditioning of the context did not occur. Neither conclusion is compatible with the tenets of associative models.

To account for retarded acquisition, both models focus on the molar aspects of the context by viewing the con- text as a unitary stimulus to which learning occurs. The context blocking model appeals to an analogy to Rescorla and Wagner's (1972) theory to account for context conditioning. Thus, with a fixed US-US interval, only the number of US preexposures should determine the amount of contextual conditioning and subsequent blocking of discrete cue conditioning. The number of sessions and the number of trials within a session should have a linear incrementing effect only if the number of USs increases with the manipulation. The results of Experiments 1 and 2 suggest that the pattern of presentations of the USs was more important than the overall number of USs. Thus, the context blocking model appears to suffer from the same problem as Rescorla and Wagner's theory in that it is not able to account for within-sessions or, in the case of the analogy, "within-trials"' effects (see Mazur \& Wagner, 1984).

Comparator models attribute retarded $\mathrm{CR}$ acquisition to the higher initial value of the expectancy of the US in the context relative to the value of the developing expectancy of the US to the CS. While the asymptotic value of the expectancy controlled by the context is determined by US density within the context during the preexposure phase, the acquisition of the expectancy is directly related to the number of US preexposures. Because the densities of US preexposure were identical for all groups in our two experiments, comparator theories would predict no between-group differences in Experiment 1 where the number of US preexposures were matched between the groups, and a monotonic function across groups in Experiment 2 where the number of US preexposure varied between groups. Neither prediction was confirmed.

The major problem with the two associative models is their focus on molar events as the basis of theoretical mechanisms. Neither approach formally allows for behavioral effects that result from temporal dynamics. A potential resolution of this problem occurs in the recent comparator model presented by Miller and Schachtman (1985), which adopts a molecular approach to contextual conditioning mechanisms. Although Miller and Schachtman's model allows for temporally localized contextual effects, the mechanisms responsible for the conditioning of localized contextual effects have not, as yet, been elucidated.

The results of Experiment 1 and 2 suggest that repeated exposures to the context in which a threshold number of US presentations occur is critical in causing retarded acquisition. Unfortunately, the results do not elucidate why repeated exposures to the context are critical. Two possibilities can be suggested. First, repeated exposures to the situation may be necessary to entrain associative processes to distinctive situational cues (Mazur \& Wagner, 1984; Saladin \& Tait, 1988). More specifically, it is possible that cues that predict the onset of the experimental session (e.g., placing the rabbits in the restraining boxes, closing chamber doors, initializing white noise, etc.) could serve to trigger associative processes, and that repeated experiences (i.e., sessions) with the sessional onset cues 
may be necessary to entrain the associative processes to the sessional onset cues. Alternatively, repeated sessions may be necessary to consolidate contextual conditioning (Moore \& Gormezano, 1977). The latter alternative would not seem necessary if the consolidation involved excitatory associations (McAllister \& McAllister, 1971), but might be necessary if inhibitory associative dynamics underlie the CR retardation effect (Saladin \& Tait, 1986).

\section{REFERENCES}

Desmond, J. E., Romano, A. G., \& Moore, J. W. (1980). Amplitude of the rabbit's unconditioned nictitating membrane response in the presence of a conditioned inhibitor. Animal Learning \& Behavior, $8,225-230$

Donegan, N. H. (1981). Priming-produced facilitation or diminution of responding to a Pavlovian unconditioned stimulus. Journal of Experimental Psychology: Animal Behavior Processes, 7, 295-312.

GibBon, J., \& Balsam, P. D. (1981). The spread of association in time In C. M. Locurto, H. S. Terrace, \& J. B. Gibbon (Eds.), Autoshaping and conditioning theory (pp. 219-253). New York: Academic Press.

Gormezano, I. (1966). Classical conditioning. In J. B. Sidowski (Ed.), Experimental methods and instrumentation in psychology (pp. 385 420). New York: McGraw-Hill.

HINSON, R. E. (1982). Effects of UCS preexposure on excitatory and inhibitory rabbit eyelid conditioning: An associative effect of conditioned contextual stimuli. Joumal of Experimental Psychology: Animal Behavior Processes, 8, 49-61.

HoBson, G. N. (1968). Effects of US adaptation upon conditioning in low and high anxiety men and women. Journal of Experimental Psychology, 76, 360-363.

Jenkins, H. M., Barnes, R. A., \& Barrera, F. J. (1981). Why autoshaping depends on trial spacing. In C. M. Locurto \& J. Gibbon (Eds.), Autoshaping and conditioning theory (pp. 255-284). New York: Academic Press.

Kamin, L. J. (1968). Attention-like processes in classical conditioning. In M. R. Jones (Ed.), Miami symposium on the prediction of be havior: Aversive stimulation (pp. 9-31). Miami: Universtiy of Miam Press.

Kamin, L. J. (1969). Predictability, surprise, attention and conditioning. In B. A. Campbell \& R. M. Church (Eds.), Punishment and aversive behavior (pp. 279-296). New York: Appleton.

KeHOE, E. J., \& Gormezano, I. (1974). Effects of trials per session on conditioning of the rabbit's nictitating membrane response. Bulletin of the Psychonomic Society, 4, 434-436.

KimmeL, H. D. (1966). Inhibition of the unconditioned response in classical conditioning. Psychological Review, 73, 232-240.

LEVENTHAL, L. F. (1973). The CS-US interval function in rabbit nictitating membrane response conditioning: Single vs. multiple trials per conditioning session. Learning \& Motivation, 4, 259-267.

LoLORDO, V. M., \& RANDICH, A. (1981). Effects of experience of electric shock upon subsequent conditioning of an emotional response: Associative and non-associative accounts. In P. Harzem \& M. D. Zeiler (Eds.), Advances in analysis of behavior: Predictability, correlation, and contiguity (Vol. 2, pp. 247-285). New York: Wiley.

MazUR, J. E., \& Wagner, A. R. (1984). An episodic model of associative learning. In M. L. Common, R. J. Herrnstein, \& A. R.
Wagner (Eds.), Quantitative analyses of behavior: Vol. 3. Acquisition (pp. 3-31). Cambridge, MA: Ballinger.

MCAllister, W. R., \& MCAllister, D. E. (1971). Behavioral measurement of conditioned fear. In F. R. Brush (Ed.), Aversive conditioning and learning (pp. 105-179). New York: Academic Press.

Miller, R. A., \&chachtman, T. R. (1985). Conditioning context as an associative baseline: Implications for response generation and the nature of conditioned inhibition. In R. R. Miller \& N. E. Spear (Eds.), Information processing in animals: Conditioned inhibition (pp. 51-88). Hillsdale, NJ: Erlbaum.

Mis, R. W., MOORE, J. W. (1973). Effects of preacquisition US exposure on classical conditioning of the rabbit's nictitating membrane response. Learning \& Motivation, 4, 108-114.

Moore, J. W., Gormezano, I. (1977). Classical conditioning. In M. H. Marx \& M. E. Busch (Eds.), Fundamentals and applications of learning (pp. 87-120). New York: Macmillan.

RANDICH, A., \& LoLoRDO, V. M. (1979). Associative and nonassociative theories of the US preexposure phenomenon: Implications for Pavlovian conditioning. Psychological Bulletin, 86, 523-548.

Rescorla, R. A., \& Wagner, A. R. (1972). A theory of Pavlovian conditioning: Variations in the effectiveness of reinforcement and nonreinforcement. In A. H. Black \& W. F. Prokasy (Eds.), Classical conditioning: II. Current theory and research (pp. 64-99). New York: Appleton-Century-Crofts.

Saladin, M. E., \& TAIT, R. W. (1986). US preexposures retard excitatory and facilitate inhibitory conditioning of the rabbit's nictitating membrane response. Animal Learning \& Behavior, 14, 121-132.

SALADIN, M. E., \& TAIT, R. W. (1988). The effects of temporal locus of US preexposures on subsequent excitatory conditioning of the albino rabbit's nictitating membrane response. Manuscript submitted for publication.

SMIтH, M. C. (1968). CS-US interval and US intensity in classical conditioning of the rabbit's nictitating membrane response. Journal of Comparative \& Physiological Psychology, 66, 679-687.

Solomon, R. L., \& CoRBIT, J. D. (1974). An opponent-process theory of motivation: I. Temporal dynamics of affect. Psychological Review, 81, 119-145.

Suboski, M. D., Dilollo, V., \& Gormezano, I. (1964). Effects of unpaired pre-acquisition of CS and US on classical conditioning of the nictitating membrane response of the albino rabbit. Psychological Reports, 15, 571-576.

TAIT, R. W., GoRmezano, I. (1974). A microcomputer program for stimulus control and analog data for discrete trials paradigms in biological preparation: Classical conditioning. Behavior Research Methods \& Instrumentation, 6, 295-300.

TAYLOR, J. A. (1956). A level of conditioning and the intensity of the adaptation stimulus. Journal of Experimental Psychology, 51, 127-130.

TERRY, W. S. (1976). The effects of priming unconditioned stimulus representations in short-term memory on Pavlovian conditioning. Journal of Experimental Psychology: Animal Behavior Processes, 2, 354-369.

Tomie, A. (1976). Retardation of autoshaping: Control by contextual stimuli. Science, 192, 1244-1246.

Tomie, A., MURPHY, A., FA Th, S., \& JACKSON, R. L. (1980). Retardation of autoshaping following pretraining with unpredictable food: Effects of changing the context between pretraining and testing. Learning \& Motivation, 11, 117-134.

(Manuscript received February 10, 1988; revision accepted for publication August 18, 1988.) 